\title{
Enhanced cytotoxicity and decreased CD8 dependence of human cancer-specific cytotoxic $T$ lymphocytes after vaccination with low peptide dose
}

\author{
Tanja Lövgren · Petra Baumgaertner · Sébastien Wieckowski Estelle Devêvre • \\ Philippe Guillaume · Immanuel Luescher • Nathalie Rufer • Daniel E. Speiser
}

Received: 29 April 2011/Accepted: 24 October 2011/Published online: 12 November 2011

(C) Springer-Verlag 2011

\begin{abstract}
In mice, vaccination with high peptide doses generates higher frequencies of specific CD8+ T cells, but with lower avidity compared to vaccination with lower peptide doses. To investigate the impact of peptide dose on $\mathrm{CD} 8+\mathrm{T}$ cell responses in humans, melanoma patients were vaccinated with 0.1 or $0.5 \mathrm{mg}$ Melan-A/MART-1 peptide, mixed with CpG 7909 and Incomplete Freund's adjuvant. Neither the kinetics nor the amplitude of the Melan-A-specific CD8+ T cell responses differed between the two vaccination groups. Also, CD8 $+\mathrm{T}$ cell differentiation and cytokine production ex vivo were similar in the two groups. Interestingly, after low peptide dose vaccination, Melan-A-specific CD8+ T cells showed enhanced degranulation upon peptide stimulation, as assessed by CD107a upregulation and perforin release ex vivo. In accordance, $\mathrm{CD} 8+\mathrm{T}$ cell clones derived from low peptide dose-vaccinated patients showed significantly increased degranulation and stronger cytotoxicity. In parallel, MelanA-specific CD8 $+\mathrm{T}$ cells and clones from low peptide dose-vaccinated patients expressed lower CD8 levels, despite similar or even stronger binding to tetramers.
\end{abstract}

Electronic supplementary material The online version of this article (doi:10.1007/s00262-011-1140-1) contains supplementary material, which is available to authorized users.

T. Lövgren · P. Baumgaertner · E. Devêvre · P. Guillaume ·

I. Luescher · N. Rufer · D. E. Speiser ( $\square)$

Clinical Tumor Biology and Immunotherapy Unit,

Ludwig Center of the University of Lausanne,

Hôpital Orthopédique 05/1552, Av. Pierre-Decker 4,

1011 Lausanne, Switzerland

e-mail: doc@dspeiser.ch

S. Wieckowski · N. Rufer

University Hospital Center and University of Lausanne (CHUV),

Lausanne, Switzerland
Furthermore, CD8 + T cell clones from low peptide dosevaccinated patients bound $\mathrm{CD} 8$ binding-deficient tetramers more efficiently, suggesting that they may express higher affinity TCRs. We conclude that low peptide dose vaccination generated CD8 $+\mathrm{T}$ cell responses with stronger cytotoxicity and lower CD8 dependence.

Keywords Human $\mathrm{CD}^{+} \mathrm{T}$ cells - Peptide dose for vaccination · Tumor-antigen Melan-A/MART-1 . Melanoma

\section{Introduction}

CTL responses specific for tumor-associated antigens can be expanded in melanoma patients by peptide vaccination [1-4]. However, for protection against cancer and infection, sufficient frequencies of specific CTL are necessary $[5,6]$, as well as additional qualitative features of generated CTL responses. In general, high-avidity CTL are more efficient at target cell lysis than their low-avidity counterparts [7-12], and their presence is correlated with superior virus control in mice [7, 8, 10, 13], macaques [14] and humans $[15,16]$, and tumor rejection in a mouse model [11]. Furthermore, the presence of polyfunctional CTL has been shown to correlate with enhanced viral $[15,17]$ and tumor [5, 18] control. Thus, when evaluating CTL responses, it is important to consider not only frequencies but also avidity and functionality of induced CTL.

The characteristics of CTL responses are affected by the nature of the stimuli (e.g., antigen, immune modulators), the anatomical site and the timing of stimulation [19, 20]. During vaccine-induced responses, CTL characteristics depend on vaccination route/schedule and vaccine components (e.g., antigens, adjuvants) and their doses [4]. 
Regarding dosing, increased peptide doses were shown to induce higher numbers of specific $\mathrm{CD} 8+\mathrm{T}$ cells in mice [21-24]. However, in many cases, these cells included increased proportions of low-avidity cells as compared to lower peptide dose vaccination [8, 21, 24]. This may be explained by recruitment of low-avidity precursors, deletion of high-avidity cells, and/or CD8 downregulation induced by high peptide dose vaccination [8].

In humans, the effect of peptide dosing on specific CTL frequencies is less well established. Positive correlation between frequencies of specific CTL and administered peptide doses have been reported, mainly comparing very low doses (5-50 $\mu \mathrm{g} /$ vaccine) with higher doses [25, 26], but many studies on vaccination with peptide, including Melan-A peptide [2], showed no effect on frequencies of specific cells by increasing peptide doses [27, 28]. Probably, the lowest administered doses already induced the highest specific CTL frequencies possible with the respective vaccination approach. Such a plateau in the generated response was shown in two large randomized, double-blinded and placebo-controlled studies on the $\mathrm{HCV}$ multipeptide vaccine IC40 where lower frequencies of specific CTL were found with the lowest used dose $(0.5 \mathrm{mg})$ [29], while no differences were seen between intermediate $(2.5 \mathrm{mg})$ and high $(5 \mathrm{mg})$ peptide doses [28, 29]. However, it is also possible that technical limitations of $\mathrm{T}$ cell analysis overlooked true differences in $\mathrm{T}$ cell responses. For example, $\mathrm{T}$ cell frequencies were often determined after in vitro expansion for one or more weeks without limiting dilution techniques, precluding precise evaluation. Moreover, biological samples were taken at a single time point after vaccination, differing between studies, and time kinetics were not analyzed. Furthermore, qualitative CTL data for CTL function and avidity/affinity for antigen recognition are lacking.

Here, we analyzed CTLs from melanoma patients after vaccination with two different doses of Melan-A peptide. Vaccination with this peptide, together with $\mathrm{CpG}$ oligonucleotide (ODN) and IFA, generates strong CTL responses [3], allowing multiparameter functional analysis directly ex vivo using pMHC tetramers. Furthermore, we generated $\mathrm{CD} 8+\mathrm{T}$ cell clones, representative for in vivo TCR repertoires [30, 31], and determined functional avidity and lytic capacity. Data demonstrate that the lower peptide dose induced qualitatively superior CTL.

\section{Materials and methods}

Patients and blood samples

HLA-A*0201-positive patients with stage III-IV melanoma received monthly vaccinations s.c. with Melan-A/
MART-1 ${ }_{26-35}$ A27L analog peptide (ELAGIGILTV), at $0.1 \mathrm{mg}$ (low dose, 10 male and 6 female patients) or $0.5 \mathrm{mg}$ (high dose, 3 male and 2 female patients). Vaccine emulsions were prepared with incomplete Freund's adjuvant (IFA, Montanide ISA-51; Seppic), CpG ODN (CpG 7909/PF-3512676; Pfizer) and peptide as described elsewhere [3]. Clinical procedures were approved by the LICR protocol review committee and the ethical committee of the University Hospital of Lausanne. Peripheral blood mononuclear cells (PBMC) were prepared from peripheral blood, by Ficoll-Hypaque (GE Healthcare) density centrifugation, and frozen in liquid nitrogen in $10 \%$ dimethyl sulphoxide (DMSO; Gibco) and 50\% FCS (Gibco) in RPMI 1640 (Gibco). Standard differential blood counts were determined, to allow calculating absolute lymphocyte numbers, based on percentages identified by flow cytometry.

Flow cytometry, cell sorting and generation of $\mathrm{CD} 8+\mathrm{T}$ cell clones

Unless otherwise stated, stainings were performed with saturating concentrations of monoclonal antibodies from BD Biosciences, at $4^{\circ} \mathrm{C}$ for $20 \mathrm{~min}$, in PBS containing $0.2 \% \mathrm{BSA}$ and $2 \mathrm{mM}$ EDTA for ex vivo samples and sortings, and in PBS containing $0.2 \%$ BSA, 5 mM EDTA and $0.2 \%$ sodium azide for clones. Melan-A-specific $\mathrm{CD} 8+\mathrm{T}$ cells were stained at $4^{\circ} \mathrm{C}$ for $45 \mathrm{~min}$ with saturating amounts of PE-labeled HLA-A*0201/Melan- $\mathrm{A}_{26-35}$ analog $\mathrm{A} 27 \mathrm{~L}$ peptide tetramers [32, 33]. In addition, D227K/T228A-mutated tetramers unable to interact with CD8 (CD8-null tetramers [34, 35]) were used. A FACSVantage SE (BD Bioscience) was used for monitoring and sorting and a Gallios ${ }^{\mathrm{TM}}$ (Beckman Coulter) for other flow cytometry. CD8 $+\mathrm{T}$ cells were enriched from PBMC using CD8 microbeads (Miltenyi Biotech). Since we noted inability of IL-2 production immediately after thawing, for cytokine assessments, PBMC were incubated over night at $37^{\circ} \mathrm{C}, 5 \% \mathrm{CO}_{2}$ in $8 \%$ human serum-containing medium without IL-2 prior to CD8 enrichment.

For monitoring and sorting, tetramer-stained CD8 enriched T cells were stained with CD8-APC-Cy7, CD45 RA-ECD (Beckmann-Coulter), CD28-FITC and purified rat-anti-human CCR7 followed by goat-anti-rat immunoglobulin-APC. Cloning was performed upon sorting of Melan-A-specific CD8+ CD45RA- CCR7- (effector memory; EM) cells. Cells ( 0.5 cells/well) were cultured in Terasaki plates (Nunc), stimulated with $1 \mu \mathrm{g} / \mathrm{ml}$ phytohemagglutin (PHA HA16; Murex Biotech) and $0.5 \times 10^{6} / \mathrm{ml}$ irradiated (30 Gy) PBMC. Clones were kept at $37^{\circ} \mathrm{C}, 5 \%$ $\mathrm{CO}_{2}$ in $8 \%$ human serum-containing RPMI 1640 supplemented with $150 \mathrm{U} / \mathrm{ml}$ human IL-2 (Roche Applied Science) and were restimulated every $2-3$ weeks. T cell clones 
were generated from blood drawn after four vaccinations, and at a few occasions from earlier and later time points (2-12 vaccines). Experiments were performed between day 11 and 15 after the previous restimulation, with maximally three restimulations.

For degranulation and cytokine assessment, 200,000480,000 tetramer-stained CD8 $+\mathrm{T}$ cells or 400,000 clone cells were added to 96-well flat-bottom plates, in $0.1 \mathrm{ml}$ $10 \%$ FCS RPMI 1640 with CD107a-PE-Cy5 and 200,000 $\mathrm{T} 2$ cells, alone or pre-pulsed with $10 \mu \mathrm{M}$ Melan-A peptide at $37^{\circ} \mathrm{C}, 1 \mathrm{~h}$. After $4 \mathrm{~h}$ at $37^{\circ} \mathrm{C}, 5 \% \mathrm{CO}_{2}$, cells were harvested and stained with CD8-APC-H7 (ex vivo experiments) or CD8-Pacific blue (clones), and $\alpha \beta$ TCR-PE. Staining with Live/Dead fixable aqua stain (InVitrogen), diluted in PBS, was performed at $4^{\circ} \mathrm{C}$ for 30 min with pure PBS washes before and after. Cells were fixed with $1 \%$ paraformaldehyde, $2 \%$ glucose and $5 \mathrm{mM}$ sodium azide in PBS at $4{ }^{\circ} \mathrm{C}$ over night before intracellular staining in $0.1 \%$ saponin (Sigma) with TNF- $\alpha$-Alexa700, IFN- $\gamma$-PE-Cy7 and rat-anti-human IL2-APC and, in ex vivo samples also Granzyme B-ECD and Perforin-FITC. In clones, perforin and granzyme B expression was assessed separately by staining with CD8-APC-H7, Live/Dead fixable aqua, fixation, and intracellular Granzyme B-ECD and PerforinFITC.

\section{Chromium release assays}

Clones were examined for lytic capacity with ${ }^{51} \mathrm{Cr}$ labeled T2 (HLA-A*0201+/Melan-A-) or C1R cells, the latter transfected with wild type or D227K/T228A mutated HLAA*0201. Duplicate wells with 10,000 effector cells, 1,000 target cells and Melan-A peptide titrated in tenfold dilutions from $1 \times 10^{-6} \mathrm{M}$ to $1 \times 10^{-12} \mathrm{M}$ or unspecific peptide (influenza matrix protein $_{58-66}$ peptide; GILGFVFTL) were used. Tumor cell recognition was measured in duplicates of $30,000,10,000,3,000$ or 1,000 clone cells and $1,000{ }^{51} \mathrm{Cr}$ labeled HLA-A*0201+/Melan-A+ Me290 or HLA-A*0201+/Melan-A- Na8 melanoma cell lines with or without $1 \times 10^{-6} \mathrm{M}$ Melan-A peptide. Spontaneous lysis in target cells alone and maximum lysis with $1 \mathrm{M} \mathrm{HCl}$ addition was measured. After $4 \mathrm{~h}$ at $37^{\circ} \mathrm{C}$, $5 \% \mathrm{CO}_{2}$, supernatants were transferred to LumaPlate ${ }^{\mathrm{TM}}$ 96-well plates (PerkinElmer) and measured with a Top Count NXT plate reader (PerkinElmer).

Detection of mRNA for Fas ligand, granzyme B and perforin

Lysis and cDNA synthesis from 10,000 cells per reaction were performed in one step before PCR [36]. Fas ligand (Forward: 5'-GGGCCCCTCCAGGCACAGTT-3', Reverse: 5'-CTGCT
GCGGGCCCACATCTG-3'), Granzyme B (Forward: $5^{\prime}$-AG ATGCAACCAATCCTGCTT-3', Reverse: $5^{\prime}$-TCTGGG TCCCCCACGCACA- $3^{\prime}$ ), perforin (Forward: $5^{\prime}$-GGCTGG TGCAAGGAGCCACA-3', Reverse: 5'-GCGGATGCTAC GAGCCGCAT- $3^{\prime}$ ) and CD3 (Forward: $5^{\prime}$-GCGGCAGGC AAAGGGGACAA-3' ${ }^{\prime}$, Reverse: $5^{\prime}$-GCCAGCGGGAGGCA GTGTTC- $3^{\prime}$ ) specific primers were used and a program of 5 initial minutes at $95^{\circ} \mathrm{C}$, thereafter 30 cycles of $30 \mathrm{~s}$ at $95^{\circ} \mathrm{C}$, $30 \mathrm{~s}$ at $63^{\circ} \mathrm{C}$ and $30 \mathrm{~s}$ at $72^{\circ} \mathrm{C}$, and finally $72^{\circ} \mathrm{C}$ for $1 \mathrm{~min}$, on a $\mathrm{T} 1 \mathrm{Thermocycler}$ (Biometra). The cDNA quality was assured by $\mathrm{CD} 3$ mRNA detection.

Data analysis and statistics

Comparison between groups was performed with unpaired $t$ test or, where mentioned, Fisher's exact test. Flow cytometry data were analyzed with FlowJo 7.6 (TreeStar) employing a gating strategy with a live lymphocyte gate in forward (FSCA) and side-scatter (SSC-A), doublet-exclusion (FSC-A/FSC$\mathrm{H}$ and SSC-A/SSC-H) and dead cell-exclusion with a dead cell marker. Quadrant/gate percentages or geometrical mean MFI values were exported and, for CD107a and cytokines, mock background MFI was subtracted. Release of perforin was calculated as (\%perforin + cells in mock - \%perforin + cells in T2_peptide stimulated samples)/\%perforin + cells in mock. Absolute numbers of specific cells per liter of blood were calculated as (leukocyte count/liter of blood) $\times \%$ lymphocytes $\times \% \mathrm{CD} 8+$ cells $\times \%$ Melan-A tetramer + cells. Specific lysis in percentage was calculated as $100 \times$ (experimental release - spontaneous release)/(total release spontaneous release), and half maximal effective concentration (EC50) was calculated by GraphPad Prism 5 (GraphPad Software) and the "log (agonist) versus response (three parameters)" sigmoid model. In tumor cell recognition experiments, lytic units (LU) within $1 \times 10^{7} \mathrm{~T}$ effector cells were calculated, with one lytic unit being defined as the number of effector cells needed for $30 \%$ specific lysis. Outliers where the range of tested effector to target ratios did not encompass the $30 \%$ target cell lysis were set as $<333$ or $>10,000$ L.U. per $10^{7}$ which prevents direct statistical comparison [37].

\section{Results}

Similar frequency, differentiation and cytokine production of Melan-A-specific CD8+ T cells after vaccination with low and high peptide doses

Patients received monthly vaccinations s.c. with different doses of Melan-A peptide, i.e., $0.1 \mathrm{mg}$ ("low dose") or $0.5 \mathrm{mg}$ ("high dose"), supplemented with CpG ODN and 
IFA. Flow cytometric monitoring was performed at several time points after vaccination to determine frequencies and differentiation status of Melan-A-specific CD8+ T cells (Fig. 1a-e, Suppl Fig 1a and b). Comparing low versus high peptide dose-vaccinated patients, we found no significant differences in maximally reached Melan-A-specific CD8+ T cell frequencies (Fig. 1b, Suppl Fig 1a), and no difference in the number of vaccinations needed to reach this maximum response (Fig. 1c). As previously reported [3], most of the specific cells were CD45RA- CCR7effector memory (EM) cells, and smaller proportions CD45RA+ CCR7 - effector (EMRA) cells, while very few were of CD45RA+ CCR7+ naïve or CD45RA- CCR7+ central memory (CM) phenotype (Fig. 1d). Finally, substantial proportions of the EM and smaller proportions of the EMRA lacked CD28 expression (Fig. 1e), a feature associated with enhanced effector differentiation [38, 39]. Thus, vaccinations were efficient, without apparent impact of the peptide dose on $\mathrm{T}$ cell differentiation.

To analyze $\mathrm{T}$ cell function, blood-derived CD8+ T cells obtained after 4 or 5 monthly vaccinations were labeled with Melan-A tetramers, stimulated with peptide-pulsed T2 cells for $4 \mathrm{~h}$ and stained intracellularly for TNF- $\alpha$ and IL-2 (Fig. 2a). Due to technical limitations, we could not simultaneously include extended phenotyping, which was however not a major limitation since most specific cells were known to be EM and EMRA cells (Fig. 1d). We found that there were no significant differences between vaccination groups in percentages of TNF- $\alpha$ (Fig. 2b) and IL-2 (Fig. 2c) positive cells, or amounts of each cytokine produced per cell (measured as MFI; results not shown).

Increased target cell lysis due to enhanced degranulation by Melan-A-specific CD8 $+\mathrm{T}$ cells from low peptide dose-vaccinated patients

For more detailed analysis of $\mathrm{T}$ cell function, Melan-Aspecific $\mathrm{CD} 8+\mathrm{T}$ cell clones were generated from PBMC of the two patients groups, by sorting Melan-A tetramer+ EM cells (Suppl Fig 1b). In accordance with ex vivo findings, clones from the two vaccination groups produced similar levels of IL- 2 and TNF- $\alpha$ upon $4 \mathrm{~h}$ peptide stimulation (results not shown). However, cytotoxicity assays revealed that clones derived from low peptide dose-vaccinated patients lysed Melan-A peptide-pulsed target cells significantly better than clones from high dose-vaccinated patients (Fig. 3a). In fact, clones from each low peptide dose-vaccinated patient had a mean maximal lysis that was higher than each one of the high peptide dose-vaccinated patients (Suppl Fig 2b). To further investigate importance of differences in lytic capacity, we measured lysis of the naturally Melan-A-expressing melanoma cell line Me290, and the Melan-A negative melanoma cell line Na8. We
A
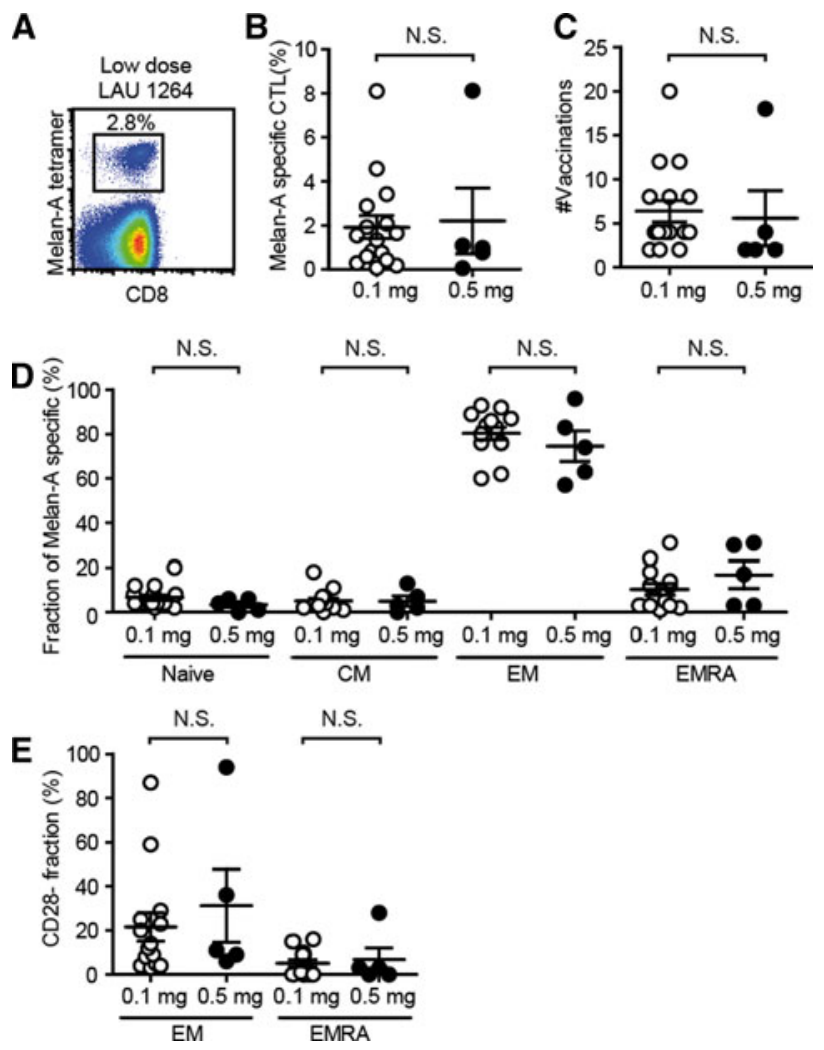

Fig. 1 Similar frequencies and differentiation of Melan-A-specific $\mathrm{CD} 8+\mathrm{T}$ cells after vaccination with low and high peptide doses. Percentages of circulating Melan-A-specific cells in CD8 $+\mathrm{T}$ cells after vaccination with $0.1 \mathrm{mg}$ peptide (low dose; $n=16$ patients) and $0.5 \mathrm{mg}$ peptide (high dose; $n=5$ ) determined directly ex vivo by flow cytometry. Shown are a representative dot plot of ex vivo MelanA-specific CD8 + T cells in patient blood after four vaccinations (a), percentages of Melan-A-specific T cells at time of peak response (b), the number of vaccinations needed to reach this peak (c) and the differentiation status of the specific $\mathrm{CD} 8+\mathrm{T}$ cells, determined as fraction of naïve $(\mathrm{CCR} 7+\mathrm{CD} 45 \mathrm{RA}+)$, central memory (CM; CCR7+ CD45RA-), effector memory (EM; CCR7-, CD45RA-) and effector RA+ (EMRA; CCR7-, CD45RA+) cells within MelanA-specific CD8+ T cells (d) and fraction of CD28-cells (e) in MelanA-specific EM or EMRA subpopulations. Data points for each patient and mean \pm SEM are shown. N.S. not significant

calculated specific lysis (Suppl Fig 2c) and lytic units per $1 \times 10^{7}$ effector cells (Fig. 3b). We found a trend toward stronger lysis of Me290 cells by CD8+ T cell clones from low peptide dose-vaccinated patients, which was also found after adding saturating amounts $(1 \mu \mathrm{M})$ of peptide. As expected, Na8 cells were poorly lysed in absence of synthetic peptide, but after addition of $1 \mu \mathrm{M}$ Melan-A peptide, clones from the low peptide dose-vaccinated group lysed $\mathrm{Na} 8$ cells better than clones from the high peptide dose group.

To determine the cause of decreased cytotoxicity in clones from high peptide dose-vaccinated patients, we assessed the capacity of degranulation. This was done by $4 \mathrm{~h}$ stimulation with peptide-pulsed T2 cells and cell-surface 
Fig. 2 Equal capacity of cytokine production by MelanA-specific CD8+ T cells from patients vaccinated with low and high doses of Melan-A peptide. CD8 + T cells from low $(n=6)$ and high $(n=5)$ dosevaccinated patients were analyzed directly ex vivo, upon triggering with unpulsed or Melan-A peptide-pulsed T2 cells for $4 \mathrm{~h}$, followed by intracellular staining for TNF- $\alpha$ $(\mathbf{a}, \mathbf{b})$ and IL-2 (a, c). Dot plots of Melan-A-specific CD8+ T cells are shown from two representative patients (a) and percentages of cytokine positive cells for each patient, with mean $\pm \operatorname{SEM}(\mathbf{b}, \mathbf{c})$

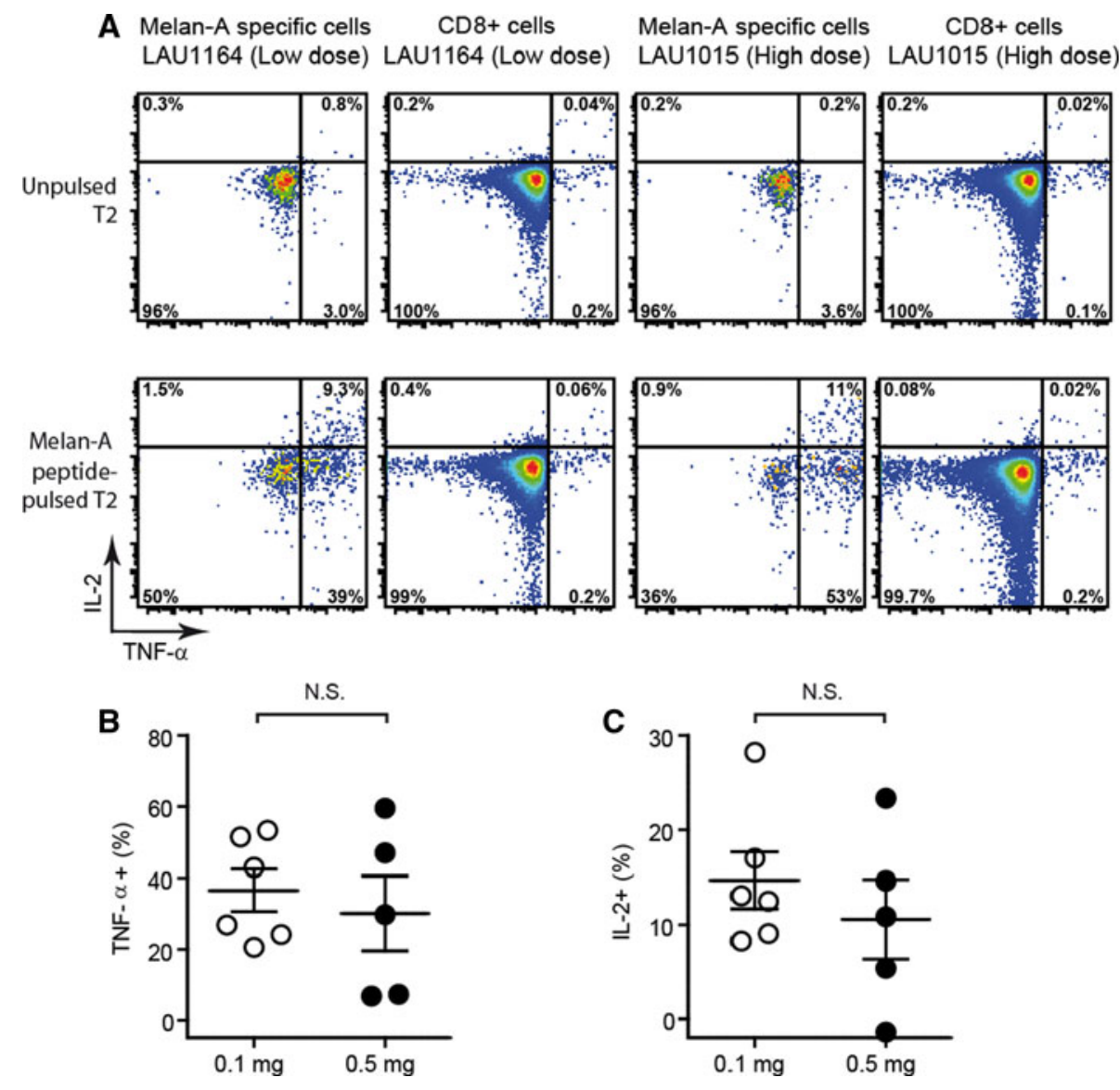

staining for CD107a/LAMP-1 (Fig. 3c), an endosome marker appearing on the cell-surface upon degranulation [40]. In Melan-A-specific CD8+ T cells analyzed ex vivo, we observed a trend toward higher cell-surface expression of CD107a on cells from low peptide dose-vaccinated patients, when measured as fraction of CD107a-positive cells (Fig. 3d), or as level of expression on individual cells (Fig. 3e). Consistent with these findings, CD107a expression was significantly higher on clones from the low peptide dose-vaccinated group (Fig. 3f, Suppl Fig 1e).

In contrast to CD107a, the percentages of perforin and granzyme B positive Melan-A-specific CD8 $+\mathrm{T}$ cells were slightly lower after low peptide dose vaccination (Fig. 4a, b and Suppl Fig 1c). In parallel, we also found slightly reduced mean fluorescence intensities of staining for perforin and granzyme B (Fig. 4d, e). However, percentages of Melan-A-specific CD8 $+\mathrm{T}$ cells that lost their perforin content after stimulation with peptide-loaded $\mathrm{T} 2$ cells were significantly higher in the low peptide dose-vaccinated group (Fig. 4c, Suppl Fig 1c). This is consistent with stronger degranulation, resulting in reduced amounts of intracellular perforin [40]. In contrast to perforin, granzyme B expression was not reduced (results not shown), probably due to rapid de novo synthesis of mature granzyme B, whereas perforin is synthesized as an inactive precursor not recognized by the antibody used [41]. In clones generated from the two patient groups, the perforin and granzyme B levels were similar, on the protein (Fig. 4f, g and Suppl Fig 1d) and also on the mRNA level (Table 1). We also analyzed mRNA expression of Fas ligand (CD178) that induces cytotoxicity via ligation with Fas (CD95) death receptor on target cells. Fas ligand was detected in very few clones, almost exclusively from the high peptide dose vaccination group (Table 1).

Reduced CD8 dependence of Melan-A-specific CD8+ $\mathrm{T}$ cells from low peptide dose-vaccinated patients

A central parameter for $\mathrm{T}$ cell functional competence is avidity for cognate antigen expressing target cells. To determine the "functional avidity" of cells generated after vaccination with the two different peptide doses, cytotoxic assays were performed with graded concentrations of peptide used for $\mathrm{T} 2$ target cell labeling, and peptide concentration required for half maximal lysis EC50 was determined. We found no difference in functional avidity between Melan-A-specific clones from the two patient groups (Fig. 5a). Most clones had functional avidities (i.e. EC50) in the range of $1 \times 10^{-12}$ to $1 \times 10^{-9} \mathrm{M}$. In addition, clones with EC50-values of $>1 \times 10^{-10} \mathrm{M}$ were 

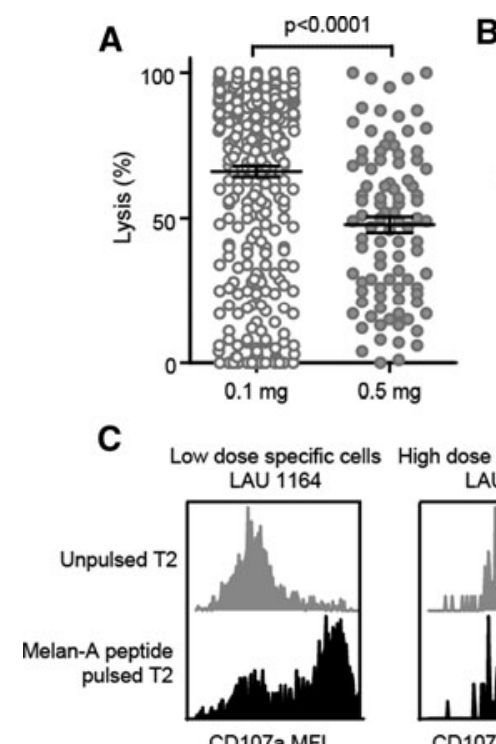

CD107a MFI
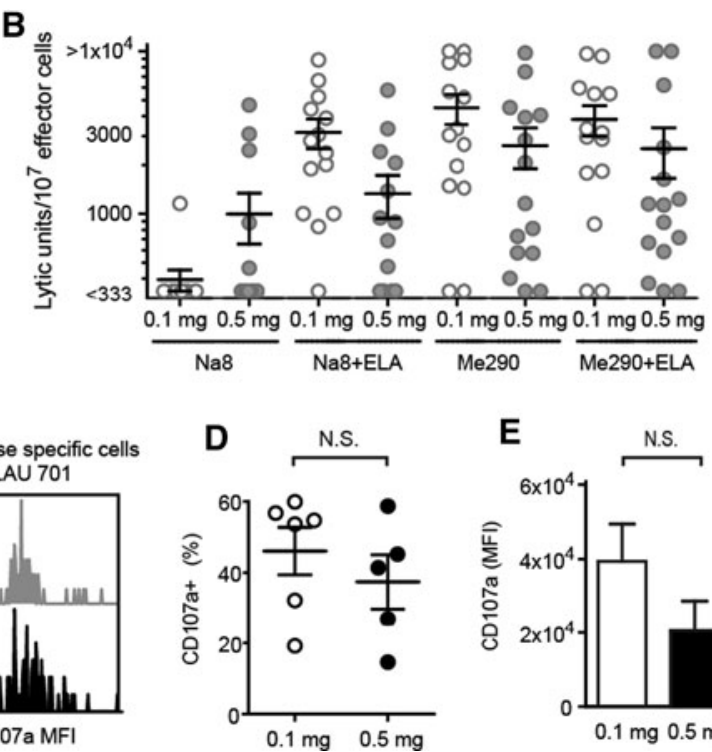

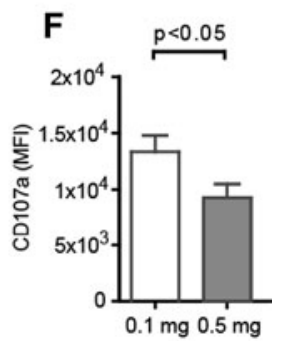

Fig. 3 Superior capacity of degranulation and target cell lysis by Melan-A-specific CD8+ T cells from low peptide dose-vaccinated patients. Melan-A-specific CD8+ clones were assessed for ability to lyse Melan-A peptide-pulsed T2 target cells (a, $n=323$ for low, $n=94$ for high peptide dose) or melanoma cell lines (b, $n=14$ for low, $n=15$ for high peptide dose) positive (Me290) or negative (Na8) for Melan-A expression, with (+ELA) and without additional peptide. Percent specific lysis (a) or lytic units within $10^{7}$ effector cells (b) are shown as individual data points for each clone, and mean \pm SEM for the two patient groups. Ability of ex vivo Melan-A- specific CD8 $+\mathrm{T}$ cells $(\mathbf{c}-\mathbf{e}, n=6$ for low, $n=5$ for high peptide dose) or clones (f, $n=22$ for low, $n=17$ for high peptide dose) to degranulate was measured as surface expression of CD107a during peptide stimulation. Shown are representative histograms for CD107a expression by Melan-A-specific CD8+ T cells analyzed ex vivo (c), after stimulation with T2 cells without or with Melan-A peptide. Percentages of positive cells (d) or expression per cell (e, mean MFI \pm SEM) by ex vivo Melan-A-specific CD8+ $\mathrm{T}$ cells, or by Melan-A-specific clones (f, mean MFI \pm SEM) for each specified group are depicted
A
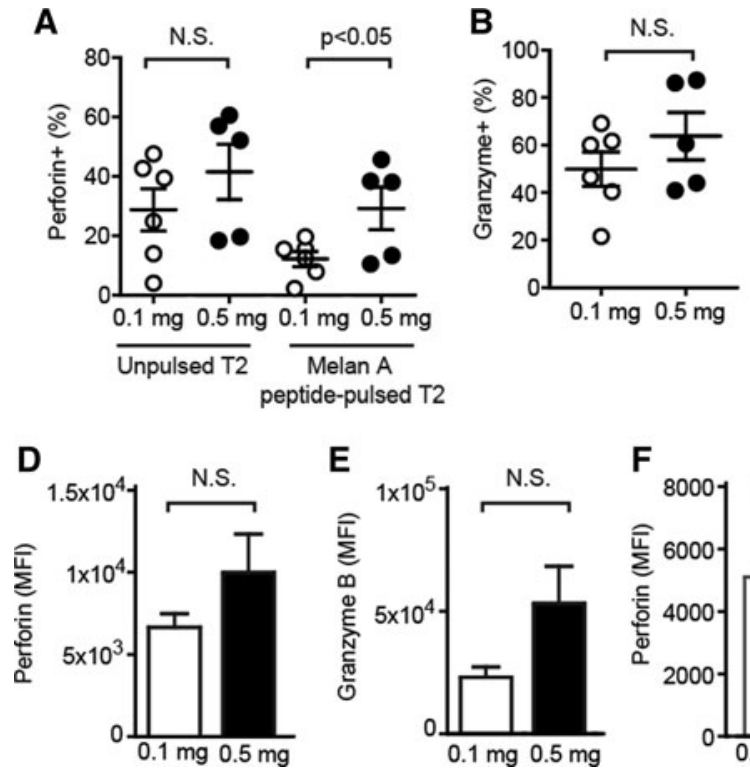

Fig. 4 Similar steady-state expression of perforin/granzyme B, but increased capacity of perforin release by Melan-A-specific CD8+ T cells from patients vaccinated with low peptide dose. Intracellular staining of perforin $(\mathbf{a}, \mathbf{c}, \mathbf{d})$ and granzyme $\mathrm{B}(\mathbf{b}, \mathbf{e})$ was performed in ex vivo Melan-A-specific CD8 $+\mathrm{T}$ cells $(\mathbf{a}-\mathbf{e}, n=6$ for low, $n=5$ for high peptide dose) or Melan-A-specific CTL clones (f, $\mathbf{g})$ from vaccinated patients. Depicted are percentages of perforin (a) or
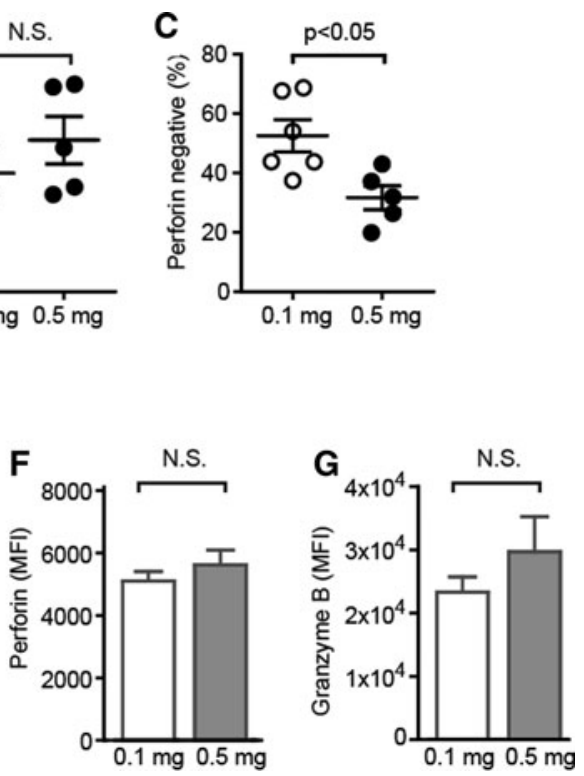

granzyme B (b) positive Melan-A-specific CD8+ T cells for the two patient groups, or percentages of specific cells that lost intracellular expression of perforin upon $4 \mathrm{~h}$ stimulation with peptide-loaded target cells (c). Results are shown per patient/clone as well as mean \pm SEM. Also shown are mean MFI \pm SEM for specific cells (d, e) or clones (f, $\mathbf{g} ; n=43$ for low, $n=20$ for high peptide dose) 
Table 1 mRNA expression for effector molecules in CD8+ T cell clones

\begin{tabular}{llll}
\hline Detected mRNA & \multicolumn{2}{l}{ Clones } & \\
\cline { 2 - 4 } & $0.1 \mathrm{mg}$ & $0.5 \mathrm{mg}$ & $P$ value \\
\hline Fas ligand & $5.6^{\mathrm{a}}$ & 26 & $P<0.05^{\mathrm{b}}$ \\
Perforin & 8.3 & 21 & N.S. \\
Granzyme B & 50 & 47 & N.S. \\
\hline
\end{tabular}

N.S. not significant

${ }^{\text {a }}$ Percentages of clones with detectable levels of Fas ligand, perforin or granzyme B mRNA

b Significance was calculated with Fisher's exact test
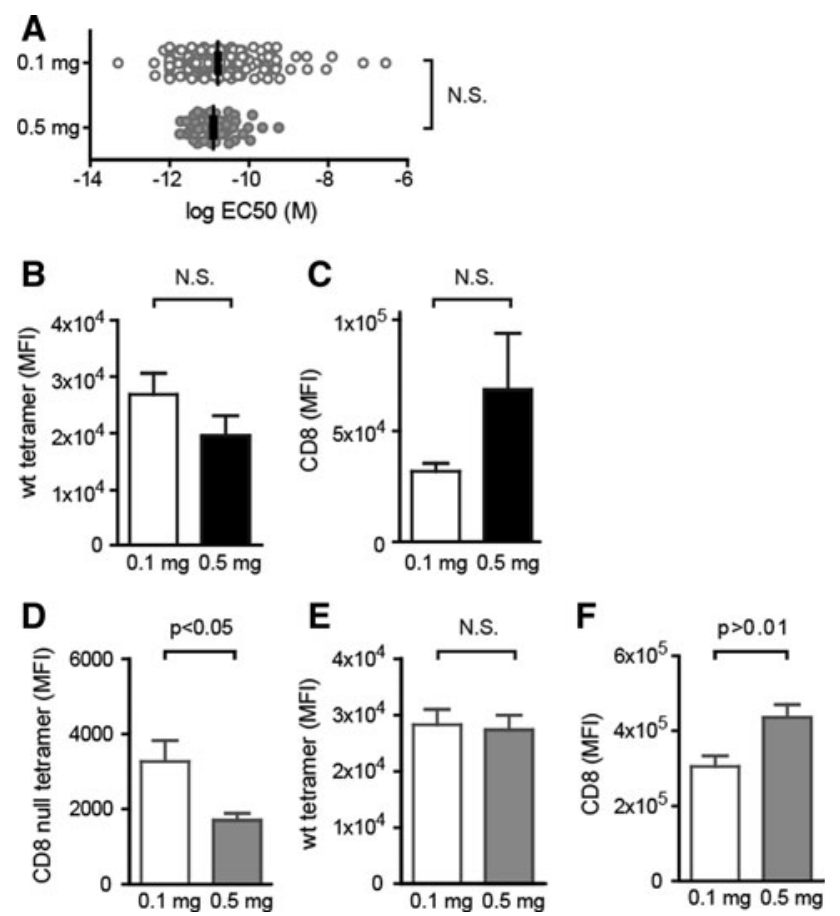

Fig. 5 Decreased CD8 dependence but similar avidity of Melan-Aspecific CD8 $+\mathrm{T}$ cells from low peptide dose-vaccinated patients. Functional avidity of Melan-A-specific clones was determined as $\operatorname{logEC50}(\mathrm{M})$ of Melan-A peptide (a). Values are depicted as separate data points and mean \pm SEM for the specified group (low peptide dose: $n=247$, high peptide dose: $n=60$ ). Ex vivo CD8+ T cells (b, c; $n=6$ for low, $n=5$ for high peptide dose) or Melan-Aspecific CD8+ T cell clones (d-f; CD8: $n=43$ for low, $n=20$ for high peptide dose, tetramers: $n=29$ for low, $n=20$ for high peptide dose) from vaccinated patients were stained with wild-type Melan-A tetramers $(\mathbf{b}, \mathbf{e})$ or for $\mathrm{CD} 8(\mathbf{c}, \mathbf{f})$. Clones were also stained with mutated Melan-A tetramer unable to bind CD8 (d). Mean MFI \pm SEM is depicted for clones from each specified group

found in almost all patients and were not more common in the high peptide dose-vaccinated group (Suppl Fig 2a).

Two major factors influencing avidity are the capacity of the $\mathrm{T}$ cell to bind peptide/MHC complexes via the TCR and via $\mathrm{CD} 8$. We analyzed tetramer binding, as well as CD8 expression levels in Melan-A-specific cells. We found a trend to weaker tetramer staining (Fig. 5b) and higher CD8 expression (Fig. 5c) in Melan-A peptide-specific cells from patients vaccinated with the high peptide dose.

On clones, staining with wild-type Melan-A tetramer was similar in the two vaccination groups (Fig. 5e). However, using mutated HLA-A*0201 (D227K/T228A) tetramers that are unable to bind CD8 ("CD8-null tetramers"), clones from high peptide dose-vaccinated patients showed significantly lower staining (Fig. 5d). Furthermore, CD8 expression levels were significantly higher on clones from high peptide dose-vaccinated patients (Fig. 5f). Higher CD8 expression and stronger CD8 dependence of Melan-A-specific $\mathrm{T}$ cells from high peptide dose-vaccinated patients suggest that these $T$ cells compensate lower affinity TCRs with enhanced CD8 function.

\section{Discussion}

In this study, we investigated whether the dose of peptide used for vaccination affected frequency, functionality, cellular composition or avidity of the responding CD8+ T cells. As reported previously, vaccination with Melan-A peptide, CpG and IFA induced high levels (up to 8\%) of specific CTL, well detectable ex vivo [3]. This is in contrast to many other cancer vaccination studies that required one or several weeks of in vitro $\mathrm{T}$ cell expansion to reach detectable levels of antigen-specific $\mathrm{T}$ cells.

Vaccination with high doses of antigen in mice has shown to result in increased CD8 $+\mathrm{T}$ cell frequencies [2124]. In melanoma patients, up to $38 \%$ of antigen-specific $\mathrm{CD} 8+\mathrm{T}$ cells were reported to be induced by vaccination with gp100 peptide and IFA [42]. This was achieved with high doses of peptide $(1 \mathrm{mg})$ per injection, and frequent (weekly) booster vaccinations (up to 40 vaccinations), resulting in high cumulative peptide doses (20- to 100-fold higher than in our study). It remains to be determined which of these parameters are more important for $\mathrm{T}$ cell quantity and quality, respectively. In our study, similar to most other studies in humans, there were no marked differences in frequencies of tumor-specific $\mathrm{T}$ cells generated with different doses of peptide [2, 27, 28]. Conversely, in terms of $\mathrm{T}$ cell function, we observed enhanced degranulation upon peptide triggering in $\mathrm{CD} 8+\mathrm{T}$ cells from low peptide dose-vaccinated patients, revealing increased functionality. In accordance, we found significantly increased degranulation in $\mathrm{CD} 8+\mathrm{T}$ cell clones from low peptide dose-vaccinated patients. Consequently, ability of clones from low peptide dose-vaccinated patients to lyse peptide-pulsed target cells was significantly increased. Similarly, the ability to lyse melanoma cells naturally expressing Melan-A was more efficient, indicating that low 
peptide dose vaccination selectively promoted degranulation and thereby cytotoxic capacity of specific $\mathrm{T}$ cells.

We found no differences in proportions of CD8 $+\mathrm{T}$ cell subsets (naïve, CM, EM, EMRA cells), positive or negative for CD28 expression. Also, the expression of perforin and granzyme B was similar. Therefore, increased cytotoxicity of CD8+ T cells after low peptide dose vaccination was due to enhanced TCR triggering, and/or improved signaling leading to more efficient lytic granule release.

Vaccination of mice with higher peptide doses has been reported to result in lower avidity $\mathrm{T}$ cells $[8,21,24]$. We found no difference in functional avidity in clones from low or high peptide dose-vaccinated patients. However, binding to peptide/MHC was stronger, and CD8 expression was lower after low peptide dose vaccination. Since CD8 contributes to tetramer binding [34], our findings suggest higher TCR affinity that is counter-acted by lower CD8 expression after low peptide dose vaccination. This is confirmed by the finding of significantly stronger CD8-null tetramer staining of $\mathrm{T}$ cell clones from low peptide dose-vaccinated patients. We also investigated the impact of the decreased CD8 dependency in Melan-A-specific CD8+ T cells from low peptide dose-vaccinated patients, by performing lysis assays with target cells expressing CD8-null MHC. However, due to low cytotoxicity in absence of CD8 involvement, we were unable to determine their functional avidity and could therefore not formally demonstrate binding differences. Our data support the notion that $\mathrm{T}$ cells with higher functional avidity still require CD8 for efficient interaction with target cells, despite that they may be less CD8 dependent. Together, our findings are compatible with the well-known ability of $T$ cells to modulate their avidity by constant tuning of CD8 expression [43-46], which appears to be a fundamental mechanism for the adaption of $\mathrm{T}$ cell avidity as part of the complex regulation of immune responses.

Our findings are remarkable in the sense that they show that even small changes in peptide dose (i.e., fivefold) can affect the quality of the generated CD8 $+\mathrm{T}$ cell response in vivo to a small but nevertheless significant degree. Furthermore, they highlight the importance of not only measuring frequencies of specific $\mathrm{T}$ cells, but also investigating their functionality. There were no obvious differences in progression free survival and overall survival between patients vaccinated with low versus high peptide dose (results not shown). However, this study was not designed for statistical analysis of clinical outcome, which would require larger patient numbers.

Our data provide a rationale for future vaccination trials, using carefully selected antigens and adjuvants eliciting $\mathrm{T}$ cell responses with multiple tumor-antigen specificities, whereby low antigen doses may promote strong $\mathrm{T}$ cell responses. Very low peptide doses, at least for initial vaccinations, have been suggested to result in higher fractions of high-avidity cells [47]. In our study, the lower peptide dose resulted in activation of $\mathrm{T}$ cells with improved degranulation and cytotoxic capacity and reduced CD8 dependence.

Acknowledgments We are obliged to patients and blood donors for their dedicated collaboration. We gratefully acknowledge L. J. Old, J. O'Donnell-Tormey, E. W. Hoffman, O. Michielin, A. Auteri, G. Berthod and K. Homicsko for their contributions, H. R. MacDonald, P. Romero, J. Skipper, H. F. Oettgen and H. Märki, for support, and P. Schneider, T. Brunner, E. Wattrang, H. Bouzourene, L. Baitsch, M. Braun, C. Meyer, A. Legat, D. Labes, M. Iancu, B. Gupta, J. -P. Rivals, L. Derré, C. Touvrey, K. Servis, L. Pan and R. Venhaus for collaboration and advice. We thank J. -M. Tiercy and V. Aubert for HLA typing, and Pfizer and Coley Pharmaceutical Group (USA) for providing CpG 7909 (PF-3512676). We are also thankful for the excellent help of C. Beauverd, C. Geldhof, L. Cagnon, L. Leyvraz, N. Montandon, E. Cuennet, and M. van Overloop. The study was supported by Swiss Cancer League grant 02279-08-2008, Swiss National Science Foundation, Swiss National Center of Competence in Research (NCCR) Molecular Oncology, Ludwig Institute for Cancer Research, Cancer Research Institute (USA), Cancer Vaccine Collaborative, and Atlantic Philanthropies (USA).

\section{References}

1. Jaeger E, Bernhard H, Romero P, Ringhoffer M, Arand M, Karbach J, Ilsemann C, Hagedorn M, Knuth A (1996) Generation of cytotoxic T-cell responses with synthetic melanoma-associated peptides in vivo: implications for tumor vaccines with melanomaassociated antigens. Int J Cancer 66(2):162-169. doi:10.1002/ (SICI)1097-0215(19960410)66:2<162:AID-IJC4>3.0.CO;2-0

2. Cormier JN, Salgaller ML, Prevette T, Barracchini KC, Rivoltini L, Restifo NP, Rosenberg SA, Marincola FM (1997) Enhancement of cellular immunity in melanoma patients immunized with a peptide from MART-1/Melan A. Cancer J Sci Am 3(1):37-44

3. Speiser DE, Lienard D, Rufer N, Rubio-Godoy V, Rimoldi D, Lejeune F, Krieg AM, Cerottini JC, Romero P (2005) Rapid and strong human CD8 + T cell responses to vaccination with peptide, IFA, and $\mathrm{CpG}$ oligodeoxynucleotide 7909. J Clin Invest 115(3): 739-746. doi:10.1172/JCI23373

4. Speiser DE, Romero P (2010) Molecularly defined vaccines for cancer immunotherapy, and protective $\mathrm{T}$ cell immunity. Semin Immunol 22(3):144-154. doi:10.1016/j.smim.2010.03.004

5. Rizzuto GA, Merghoub T, Hirschhorn-Cymerman D, Liu C, Lesokhin AM, Sahawneh D, Zhong H, Panageas KS, Perales MA, Altan-Bonnet G, Wolchok JD, Houghton AN (2009) Self-antigen-specific $\mathrm{CD} 8+\mathrm{T}$ cell precursor frequency determines the quality of the antitumor immune response. J Exp Med 206(4): 849-866. doi:10.1084/jem.20081382

6. Venturi V, Price DA, Douek DC, Davenport MP (2008) The molecular basis for public T-cell responses? Nat Rev Immunol 8(3):231-238. doi:10.1038/nri2260

7. Derby M, Alexander-Miller M, Tse R, Berzofsky J (2001) Highavidity CTL exploit two complementary mechanisms to provide better protection against viral infection than low-avidity CTL. J Immunol 166(3):1690-1697

8. Alexander-Miller MA, Leggatt GR, Berzofsky JA (1996) Selective expansion of high- or low-avidity cytotoxic T lymphocytes and efficacy for adoptive immunotherapy. Proc Natl Acad Sci USA 93(9):4102-4107 
9. Bennett MS, Ng HL, Dagarag M, Ali A, Yang OO (2007) Epitope-dependent avidity thresholds for cytotoxic T-lymphocyte clearance of virus-infected cells. J Virol 81(10):4973-4980. doi: 10.1128/JVI.02362-06

10. Speiser DE, Kyburz D, Stubi U, Hengartner H, Zinkernagel RM (1992) Discrepancy between in vitro measurable and in vivo virus neutralizing cytotoxic $\mathrm{T}$ cell reactivities. Low $\mathrm{T}$ cell receptor specificity and avidity sufficient for in vitro proliferation or cytotoxicity to peptide-coated target cells but not for in vivo protection. J Immunol 149(3):972-980

11. Zeh HJ 3rd, Perry-Lalley D, Dudley ME, Rosenberg SA, Yang JC (1999) High avidity CTLs for two self-antigens demonstrate superior in vitro and in vivo antitumor efficacy. J Immunol 162(2):989-994

12. Yee C, Savage PA, Lee PP, Davis MM, Greenberg PD (1999) Isolation of high avidity melanoma-reactive CTL from heterogeneous populations using peptide-MHC tetramers. J Immunol 162(4):2227-2234

13. Sedlik C, Dadaglio G, Saron MF, Deriaud E, Rojas M, Casal SI, Leclerc C (2000) In vivo induction of a high-avidity, high-frequency cytotoxic T-lymphocyte response is associated with antiviral protective immunity. J Virol 74(13):5769-5775

14. Belyakov IM, Kuznetsov VA, Kelsall B, Klinman D, Moniuszko M, Lemon M, Markham PD, Pal R, Clements JD, Lewis MG, Strober W, Franchini G, Berzofsky JA (2006) Impact of vaccineinduced mucosal high-avidity CD8+ CTLs in delay of AIDS viral dissemination from mucosa. Blood 107(8):3258-3264. doi: 10.1182/blood-2005-11-4374

15. Almeida JR, Price DA, Papagno L, Arkoub ZA, Sauce D, Bornstein E, Asher TE, Samri A, Schnuriger A, Theodorou I, Costagliola D, Rouzioux C, Agut H, Marcelin AG, Douek D, Autran B, Appay V (2007) Superior control of HIV-1 replication by CD8+ T cells is reflected by their avidity, polyfunctionality, and clonal turnover. J Exp Med 204(10):2473-2485. doi:10.1084/ jem.20070784

16. Neveu B, Debeaupuis E, Echasserieau K, le Moullac-Vaidye B, Gassin M, Jegou L, Decalf J, Albert M, Ferry N, Gournay J, Houssaint E, Bonneville M, Saulquin X (2008) Selection of highavidity CD8 $\mathrm{T}$ cells correlates with control of hepatitis $\mathrm{C}$ virus infection. Hepatology 48(3):713-722. doi:10.1002/hep.22379

17. Harari A, Dutoit V, Cellerai C, Bart PA, Du Pasquier RA, Pantaleo G (2006) Functional signatures of protective antiviral T-cell immunity in human virus infections. Immunol Rev 211:236-254. doi:10.1111/j.0105-2896.2006.00395.x

18. Yuan J, Gnjatic S, Li H, Powel S, Gallardo HF, Ritter E, Ku GY, Jungbluth AA, Segal NH, Rasalan TS, Manukian G, Xu Y, Roman RA, Terzulli SL, Heywood M, Pogoriler E, Ritter G, Old LJ, Allison JP, Wolchok JD (2008) CTLA-4 blockade enhances polyfunctional NY-ESO-1 specific T cell responses in metastatic melanoma patients with clinical benefit. Proc Natl Acad Sci USA 105(51):20410-20415. doi:10.1073/pnas.0810114105

19. Appay V, Douek DC, Price DA (2008) CD8+ T cell efficacy in vaccination and disease. Nat Med 14(6):623-628. doi:10.1038/ nm.f.1774

20. Harty JT, Badovinac VP (2008) Shaping and reshaping CD8+ T-cell memory. Nat Rev Immunol 8(2):107-119. doi:10.1038/ nri2251

21. Bullock TN, Mullins DW, Engelhard VH (2003) Antigen density presented by dendritic cells in vivo differentially affects the number and avidity of primary, memory, and recall CD8 $+\mathrm{T}$ cells. J Immunol 170(4):1822-1829

22. Hamilton SE, Harty JT (2002) Quantitation of CD8+ T cell expansion, memory, and protective immunity after immunization with peptide-coated dendritic cells. J Immunol 169(9):4936-4944

23. Kochenderfer JN, Chien CD, Simpson JL, Gress RE (2007) Maximizing CD8+ $\mathrm{T}$ cell responses elicited by peptide vaccines containing CpG oligodeoxynucleotides. Clin Immunol 124(2):119_ 130. doi:10.1016/j.clim.2007.04.003

24. Narayan S, Choyce A, Fernando GJ, Leggatt GR (2007) Secondary immunisation with high-dose heterologous peptide leads to $\mathrm{CD} 8 \mathrm{~T}$ cell populations with reduced functional avidity. Eur J Immunol 37(2):406-415. doi:10.1002/eji.200535688

25. Vitiello A, Ishioka G, Grey HM, Rose R, Farness P, LaFond R, Yuan L, Chisari FV, Furze J, Bartholomeuz R et al (1995) Development of a lipopeptide-based therapeutic vaccine to treat chronic $\mathrm{HBV}$ infection. I. Induction of a primary cytotoxic $\mathrm{T}$ lymphocyte response in humans. J Clin Invest 95(1):341-349. doi:10.1172/JCI117662

26. Audran R, Lurati-Ruiz F, Genton B, Blythman HE, Ofori-Anyinam O, Reymond C, Corradin G, Spertini F (2009) The synthetic Plasmodium falciparum circumsporozoite peptide PfCS102 as a malaria vaccine candidate: a randomized controlled phase I trial. PLoS One 4(10):e7304. doi:10.1371/journal.pone.0007304

27. Greiner J, Schmitt A, Giannopoulos K, Rojewski MT, Gotz M, Funk I, Ringhoffer M, Bunjes D, Hofmann S, Ritter G, Dohner H, Schmitt M (2010) High-dose RHAMM-R3 peptide vaccination for patients with acute myeloid leukemia, myelodysplastic syndrome and multiple myeloma. Haematologica 95(7):1191-1197. doi:10.3324/haematol.2009.014704

28. Klade CS, Wedemeyer H, Berg T, Hinrichsen H, Cholewinska G, Zeuzem S, Blum H, Buschle M, Jelovcan S, Buerger V, Tauber E, Frisch J, Manns MP (2008) Therapeutic vaccination of chronic hepatitis $\mathrm{C}$ nonresponder patients with the peptide vaccine IC41. Gastroenterology 134(5):1385-1395. doi:10.1053/j.gastro.2008. 02.058

29. Firbas C, Jilma B, Tauber E, Buerger V, Jelovcan S, Lingnau K, Buschle M, Frisch J, Klade CS (2006) Immunogenicity and safety of a novel therapeutic hepatitis $\mathrm{C}$ virus (HCV) peptide vaccine: a randomized, placebo controlled trial for dose optimization in 128 healthy subjects. Vaccine 24(20):4343-4353. doi:10.1016/j.vaccine. 2006.03.009

30. Speiser DE, Baumgaertner P, Barbey C, Rubio-Godoy V, Moulin A, Corthesy P, Devevre E, Dietrich PY, Rimoldi D, Lienard D, Cerottini JC, Romero P, Rufer N (2006) A novel approach to characterize clonality and differentiation of human melanomaspecific $\mathrm{T}$ cell responses: spontaneous priming and efficient boosting by vaccination. J Immunol 177(2):1338-1348

31. Wieckowski S, Baumgaertner P, Corthesy P, Voelter V, Romero P, Speiser DE, Rufer N (2009) Fine structural variations of alphabetaTCRs selected by vaccination with natural versus altered self-antigen in melanoma patients. J Immunol 183(8):5397-5406. doi:10.4049/jimmunol.0901460

32. Pittet MJ, Valmori D, Dunbar PR, Speiser DE, Lienard D, Lejeune F, Fleischhauer K, Cerundolo V, Cerottini JC, Romero P (1999) High frequencies of naive Melan-A/MART-1-specific $\mathrm{CD} 8(+) \mathrm{T}$ cells in a large proportion of human histocompatibility leukocyte antigen (HLA)-A2 individuals. J Exp Med 190(5): $705-715$

33. Altman JD, Moss PA, Goulder PJ, Barouch DH, McHeyzer-Williams MG, Bell JI, McMichael AJ, Davis MM (1996) Phenotypic analysis of antigen-specific T lymphocytes. Science 274(5284):94-96

34. Purbhoo MA, Boulter JM, Price DA, Vuidepot AL, Hourigan CS, Dunbar PR, Olson K, Dawson SJ, Phillips RE, Jakobsen BK, Bell JI, Sewell AK (2001) The human CD8 coreceptor effects cytotoxic $\mathrm{T}$ cell activation and antigen sensitivity primarily by mediating complete phosphorylation of the $\mathrm{T}$ cell receptor zeta chain. J Biol Chem 276(35):32786-32792

35. Pittet MJ, Rubio-Godoy V, Bioley G, Guillaume P, Batard P, Speiser D, Luescher I, Cerottini JC, Romero P, Zippelius A (2003) Alpha 3 domain mutants of peptide/MHC class I multimers allow the selective isolation of high avidity tumor-reactive CD8 T cells. J Immunol 171(4):1844-1849 
36. Rufer N, Reichenbach P, Romero P (2005) Methods for the ex vivo characterization of human $\mathrm{CD} 8+\mathrm{T}$ subsets based on gene expression and replicative history analysis. Methods Mol Med 109:265-284

37. Wonderlich J, Shearer G, Livingstone A, Brooks A (2006) Induction and measurement of cytotoxic T lymphocyte activity, Chapter 3, Unit 3.11. Curr Protoc Immunol. doi:10.1002/04711 42735.im0311s72

38. Speiser DE, Migliaccio M, Pittet MJ, Valmori D, Lienard D, Lejeune F, Reichenbach P, Guillaume P, Luscher I, Cerottini JC, Romero P (2001) Human CD8(+) T cells expressing HLA-DR and CD28 show telomerase activity and are distinct from cytolytic effector T cells. Eur J Immunol 31(2):459-466. doi: 10.1002/1521-4141(200102)31:2\&\#60;459::AID-IMMU459\&\#62; 3.0.CO;2-Y

39. Romero P, Zippelius A, Kurth I, Pittet MJ, Touvrey C, Iancu EM, Corthesy P, Devevre E, Speiser DE, Rufer N (2007) Four functionally distinct populations of human effector-memory CD8+ T lymphocytes. J Immunol 178(7):4112-4119

40. Betts MR, Brenchley JM, Price DA, De Rosa SC, Douek DC, Roederer M, Koup RA (2003) Sensitive and viable identification of antigen-specific CD8 $+\mathrm{T}$ cells by a flow cytometric assay for degranulation. J Immunol Methods 281(1-2):65-78

41. Makedonas G, Banerjee PP, Pandey R, Hersperger AR, Sanborn KB, Hardy GA, Orange JS, Betts MR (2009) Rapid up-regulation and granule-independent transport of perforin to the immunological synapse define a novel mechanism of antigen-specific
CD8+ T cell cytotoxic activity. J Immunol 182(9):5560-5569. doi:10.4049/jimmunol.0803945

42. Powell DJ Jr, Rosenberg SA (2004) Phenotypic and functional maturation of tumor antigen-reactive CD8+ $\mathrm{T}$ lymphocytes in patients undergoing multiple course peptide vaccination. J Immunother 27(1):36-47

43. Maile R, Siler CA, Kerry SE, Midkiff KE, Collins EJ, Frelinger JA (2005) Peripheral "CD8 tuning" dynamically modulates the size and responsiveness of an antigen-specific $\mathrm{T}$ cell pool in vivo. J Immunol 174(2):619-627

44. Park JH, Adoro S, Lucas PJ, Sarafova SD, Alag AS, Doan LL, Erman B, Liu X, Ellmeier W, Bosselut R, Feigenbaum L, Singer A (2007) 'Coreceptor tuning': cytokine signals transcriptionally tailor CD8 coreceptor expression to the self-specificity of the TCR. Nat Immunol 8(10):1049-1059. doi:10.1038/ni1512

45. Alexander-Miller MA (2005) High-avidity CD8+ T cells: optimal soldiers in the war against viruses and tumors. Immunol Res 31(1):13-24. doi:10.1385/IR:31:1:13

46. Xiao Z, Mescher MF, Jameson SC (2007) Detuning CD8 T cells: down-regulation of CD8 expression, tetramer binding, and response during CTL activation. J Exp Med 204(11):2667-2677. doi:10.1084/jem.20062376

47. Johansen P, Storni T, Rettig L, Qiu Z, Der-Sarkissian A, Smith KA, Manolova V, Lang KS, Senti G, Mullhaupt B, Gerlach T, Speck RF, Bot A, Kundig TM (2008) Antigen kinetics determines immune reactivity. Proc Natl Acad Sci USA 105(13):5189-5194. doi:10.1073/pnas.0706296105 